\title{
EDITORIAL
}

\section{The art of medicine: recognising influenza and pneumonia}

See linked article by Nakanishi et al. on pg 421

\author{
*Wei Shen Lima \\ a Consultant Respiratory Physician, \\ Nottingham University Hospitals NHS \\ Trust, Nottingham, UK \\ *Correspondence: \\ Dr Wei Shen Lim \\ Consultant Respiratory Physician \\ Department of Respiratory Medicine \\ Nottingham University Hospitals NHS \\ Trust \\ City Hospital Campus \\ Hucknall Road \\ Nottingham \\ NG5 1PB \\ UK \\ Tel: +44 (0)1159691169 ext 59347 \\ Fax: $+44(0) 1159627723$ \\ E-mail: weishen.lim@nuh.nhs.uk
}

Commissioned article

Not externally peer-reviewed

Accepted 28th October 2011

Online 15th November 2011
Consultations for acute respiratory tract infections account for $15-20 \%$ of all primary care consultations. 'A large proportion of these patients have a mild, self-limiting illness. For the other patients, one of the recurring challenges is the decision whether to prescribe antivirals, antibiotics, or both.

In this issue of the $P C R J$, Nakanishi and colleagues ${ }^{2}$ report a retrospective cohort study attempting to describe symptoms and signs that might distinguish between community acquired pneumonia (CAP) and 2009 influenza A/H1N1 infection. Patients for the study were drawn from those presenting to the out-patient facilities of the internal medicine or emergency departments at a single institution in Japan between September 2009 and February 2010. A rapid influenza antigen detection test was used to identify patients with influenza infection (of 3464 patients tested, 718 were positive). Patients with an infiltrate on chest $x$-ray $(C X R)$ comprised the CAP cohort $(n=68)$. Patients aged $<15$ years or $>75$ years were excluded from the study, as were patients with major chronic illnesses. None of the patients in the influenza group and only 15 patients in the CAP group were admitted. The study cohort therefore comprised relatively fit adults with mild illness. Based on multivariate analyses, features associated with CAP included increasing age, sputum production, dyspnoea, chest pain and coarse crackles, while typical upper respiratory tract symptoms of rhinorrhoea and sore throat were associated with influenza infection.

Some limitations of this study are worth recognising. The precise rapid influenza antigen test used to define the influenza group was not reported; these tests mostly have good specificity (82-99\%) but only restricted sensitivity (44-95\%). ${ }^{3}$ Therefore, some patients in the CAP group (who all tested negative) may still have had influenza infection. Conversely, of the 718 patients in the influenza group, only 72 had a CXR performed. How decisions were taken regarding the need for a CXR is not reported. If patients with predominantly upper respiratory tract symptoms and without lower respiratory tract signs/symptoms were selected not to have a CXR, then selection bias might account for some of the differences reported between the two groups. In the multivariate analysis to identify distinguishing features for CAP, 19 variables were tested. As a general rule, in order to avoid overfitting of data within a multivariate model, 10 outcomes are advised for each variable tested. ${ }^{4}$ Therefore, in a cohort comprising 68 patients with CAP (the outcome variable), the multivariate model should ideally have been limited to 7 key variables.

These limitations aside, the findings from this study reflect clinical experience. Features of an acute lower respiratory tract illness, focal chest signs and systemic features of infections are all recognised to be associated with CXR-confirmed CAP and form part of the British Thoracic Society's definition of CAP diagnosed in the community. ${ }^{5,6}$ In practice, the clinical diagnosis of CAP can be difficult since patients with CAP can present with minimal respiratory symptoms, particularly the elderly. Various diagnostic prediction rules have been published but none are perfect. Clinical judgement remains critical.

The clinical diagnosis of influenza can be equally challenging. There is no globally-agreed definition of an influenza-like illness (ILI) though most definitions require at least the presence of an acute cough and a fever. Furthermore, infection by a range of viral and bacterial pathogens can cause an ILI. As expected, during the period when influenza is circulating locally, the predictive value of an ILI for laboratory confirmed influenza is higher 
(predictive value 60-70\%). ${ }^{7}$ Outside an influenza season/epidemic, the predictive value of an ILI for confirmed influenza is much lower (predictive value $25 \%$ ). Various diagnostic prediction models have also been developed for influenza. Ruling out influenza has generally been found to be easier than ruling it in - the absence of fever, cough and nasal symptoms being the most predictive features, each with negative likelihood ratios of less than $0.5 .8,9$

When faced with a patient presenting with an ILI, the question remains - should an antiviral, an antibiotic, or both, be prescribed? When influenza is known to be circulating locally, patients at risk of complications (i.e. persons aged $>65$ years or those with chronic illnesses) who present within 48 hours of onset of an ILI should probably be prescribed antivirals, ${ }^{10}$ accepting that a proportion of these patients will not have influenza. In the most recent Cochrane review, neuraminidase inhibitors were significantly associated with a shorter time to alleviation of symptoms (oseltamivir OR $1.2,95 \% \mathrm{Cl}$ 1.06 to 1.35 ; zanamivir OR $1.24,95 \% \mathrm{Cl} 1.13$ to 1.36 - i.e. treated patients were $20-24 \%$ more likely to have their symptoms alleviated by a given time-point)." There was insufficient trial evidence to determine the effect of neuraminidase inhibitors on the prevention of complications or antibiotic usage. However, data from cohort studies from the 2009 pandemic indicate that the early use of antivirals was associated with improved outcomes. ${ }^{12}$ In the UK, during the first wave of the 2009 pandemic, of patients hospitalised with subsequently confirmed 2009 influenza A/H1N1 only $15 \%$ of adults had received antivirals prior to admission. ${ }^{13}$ The main side effect from oseltamivir is nausea (OR 2.5), ${ }^{11}$ though fortunately, severe adverse side effects are very uncommon.

Perhaps more difficult is the decision whether such patients presenting with ILI should receive antibiotics in addition to antivirals. The potential value of an antibiotic is to cover bacterial pathogens: a) in case the initial diagnosis of influenza in incorrect; and/or b) in the event of secondary bacterial complications. A further decision is whether the antibiotic might be given as a delayed prescription as part of 'safety-netting' and to reduce potential re-consultation, or given immediately. ${ }^{14}$ These decisions are informed by careful consideration of clinical features to determine illness severity and the possibility of pneumonia.

\section{Conflicts of interest}

The author declares that he has no conflicts of interest in relation to this article.

\section{References}

1. Gulliford M, Latinovic R, Charlton J, Little P, van Staa T, Ashworth M. Selective decrease in consultations and antibiotic prescribing for acute respiratory tract infections in UK primary care up to 2006. J Public Health (Oxf) 2009;31(4):512-20. http://dx.doi.org/10.1093/pubmed/fdp081

2. Nakanishi M, Yoshida $\mathrm{Y}$, Takeda $\mathrm{N}$, et al. Community-acquired pneumonia distinguished from influenza infection based on clinical signs and symptoms during a novel (swine) influenza A/H1N1 pandemic. Prim Care Respir J 2011;20(4):421-26. http://dx.doi.org/10.4104/pcrj.2011.00067

3. Petric M, Comanor L, Petti CA. Role of the laboratory in diagnosis of influenza during seasonal epidemics and potential pandemics. J Infect Dis 2006;194 Suppl 2:S98-110. http://dx.doi.org/10.1086/507554

4. Concato J, Feinstein AR, Holford TR. The risk of determining risk with multivariable models. Ann Intern Med 1993;118(3):201-10.

5. Lim WS, Baudouin SV, George RC, et al. BTS guidelines for the management of community acquired pneumonia in adults: update 2009. Thorax 2009;64 Suppl 3:iii1-55. http://dx.doi.org/10.1136/thx.2009.121434

6. Levy ML, Le Jeune I, Woodhead MA, Macfarlane JT, Lim S. Primary care summary of the British Thoracic Society Guidelines for the management of community acquired pneumonia in adults: 2009 update. Endorsed by the Royal College of General Practitioners and the Primary Care Respiratory Society UK. Prim Care Respir J 2010;19(1):21-7. http://dx.doi.org/10.4104/pcrj.2010.00014

7. Michiels B, Thomas I, Van Royen P, Coenen S. Clinical prediction rules combining signs, symptoms and epidemiological context to distinguish influenza from influenza-like illnesses in primary care: a cross sectional study. BMC Fam Pract 2011;12:4. http://dx.doi.org/10.1186/1471-2296-12-4

8. Monto AS, Gravenstein S, Elliott M, Colopy M, Schweinle J. Clinical signs and symptoms predicting influenza infection. Arch Intern Med 2000;160(21):3243-7. http://dx.doi.org/10.1001/archinte.160.21.3243

9. Call SA, Vollenweider MA, Hornung CA, Simel DL, McKinney WP. Does this patient have influenza? JAMA 2005;293(8):987-97. http://dx.doi.org/10.1001/jama.293.8.987

10. NICE technology appraisal guidance 168 (2009). Amantadine, oseltamivir and zanamivir for the treatment of influenza. Available from www.nice.org.uk/TA168.

11. Jefferson T, Jones M, Doshi P, Del Mar C, Dooley L, Foxlee R. Neuraminidase inhibitors for preventing and treating influenza in healthy adults: a Cochrane review. Health Technol Assess 2010;14(46):355-458.

12. Jain S, Kamimoto L, Bramley AM, et al. Hospitalized Patients with 2009 H1N1 Influenza in the United States, April-June 2009. N Engl J Med 2009;361(20):1935-44. http://dx.doi.org/10.1056/NEJMoa0906695

13. Nguyen-Van-Tam JS, Openshaw PJ, Hashim A, et al. Risk factors for hospitalisation and poor outcome with pandemic A/H1N1 influenza: United Kingdom first wave (May-September 2009). Thorax 2010;65(7):645-51. http://dx.doi.org/10.1136/thx.2010.135210

14. NICE clinical guideline 69 (2008). Respiratory tract infections - antibiotic prescribing. Prescribing of antibiotics for self-limiting respiratory tract infections in adults and children in primary care. Available from www.nice.org.uk/CG69.

\section{Available online at http://www.thepcrj.org}

